\title{
Comunicação
}

[Communication]

\section{Prevalência de anticorpos anti-Rickettsia spp. em cães da cidade de Belo Horizonte, MG}

\author{
[Prevalence of antibodies anti-Rickettsia in dogs from Belo Horizonte, MG, Brazil]
}

\author{
M.E. Silva ${ }^{1}$, R.R. Ribeiro ${ }^{2}$, J.O. Costa ${ }^{3}$, J. Moraes-Filho ${ }^{4}$, R.C. Pacheco ${ }^{4}$, M.B. Labruna ${ }^{4}$ \\ ${ }^{1}$ EPAMIG - Pitangui, MG \\ ${ }^{2}$ Universidade Federal do Recôncavo da Bahia - Cruz das Almas, BA \\ ${ }^{3}$ Escola de Veterinária - UFMG - Belo Horizonte, MG \\ ${ }^{4}$ Faculdade de Medicina Veterinária e Zootecnia - USP - São Paulo, SP
}

\begin{abstract}
Rickettsia é uma bactéria intracelular obrigatória, pertencente à família Rickettsiaceae e à ordem Rickettsiales (Raoult e Roux, 1997). As espécies desse gênero estão divididas em dois grupos, baseados nos padrões antigênicos, moleculares e ecológicos: i - grupo do tifo (GT), composto pelas espécies Rickettsia prowazekii e Rickettsia typhi, transmitidas por piolhos e pulgas, respectivamente; ii - grupo da febre maculosa (GFM), o qual está composto por mais de 23 espécies válidas, dentre as quais predomina a transmissão por meio de carrapatos, com exceção de Rickettsia felis e Rickettsia akari associadas a pulgas e ácaros, respectivamente. Outras espécies de rickettsias de patogenicidade desconhecida, tais como Rickettsia bellii e Rickettsia canadensis, não estão inseridas em nenhum desses dois grupos (Yu e Walker, 2003).
\end{abstract}

No Brasil, a doença causada por rickettsias do GFM é denominada febre maculosa brasileira (FMB), e Rickettsia rickettsii tem sido incriminada como o principal agente etiológico. Casos confirmados de infecção por Rickettsia rickettsii tem sido relatados nos quatro estados da região Sudeste, na Bahia, em Santa Catarina, no Paraná e no Rio Grande do Sul. A transmissão da FMB ao homem e aos animais ocorre por pelo menos três espécies de carrapatos: Amblyomma cajennense, Amblyomma aureolatum e Amblyomma ovale (Guedes et al., 2005; Pinter e Labruna, 2006).

Recebido em 18 janeiro de 2010 Aceito em 20 de agosto de 2010 E-mail: manoelsilva@epamig.br Apoio: FAPEMIG
A importância do cão doméstico como hospedeiro amplificador para Rickettsia rickettsii permanece controversa na literatura, embora recentemente casos de febre maculosa por esta rickettsia no Arizona (EUA) reforçaram seu papel como hospedeiro amplificador (Demma et al., 2005).

Dentre os métodos diagnósticos, os testes sorológicos são os mais frequentemente utilizados e amplamente disponíveis em todo o mundo, sendo a reação de imunofluorescência indireta (RIFI) considerada o método sorológico de referência, por apresentar sensibilidade de $84,6 \%$ a $100 \%$ e especificidade de 99,8 a $100 \%$ (Brouqui et al., 2004). No entanto, a RIFI não permite a identificação da espécie de Rickettsia envolvida na infecção, uma vez que todas as rickettsias do GFM apresentam reação sorológica cruzada entre si (Philip et al., 1978). A origem geográfica da infecção tem sido um dos melhores indicadores de identidade das diferentes espécies de rickettsias, sendo preconizada a avaliação de amostras de soro pela RIFI a partir de possíveis espécies de rickettsias de ocorrência local, pois normalmente títulos de anticorpos homólogos a uma determinada espécie de rickéttsia são maiores que títulos heterólogos àquela espécie. Quando um título obtido para determinada espécie de Rickettsia for pelo menos quatro vezes maior que o título mais alto obtido para as demais espécies testadas, pode-se sugerir que os anticorpos são homólogos à primeira espécie (Labruna et al., 2007). 
Com o objetivo de avaliar a condição epidemiológica das riquetsioses e 0 monitoramento da FMB em Belo Horizonte, a prevalência de anticorpos anti-Rickettsia spp. em amostras de soros de cães, a partir de cinco antígenos de ocorrência no Brasil (Rickettsia rickettsii, Rickettsia parkeri, Rickettsia amblyommii, Rickettsia felis e Rickettsia bellii), foi instituída pela primeira vez no município. As amostras de soro foram coletadas em Belo Horizonte, MG, situada na região Sudeste do Brasil.

O cálculo da amostra foi realizado com auxílio do programa computacional EpiInfo version 6.0, considerando nível de confiança de 95\%, prevalência estimada de 4\% (Labruna et al., 2007) e erro esperado de $2 \%$, o que resultou em amostra de 369 cães. Para evitar que possíveis perdas de material durante a coleta e o processamento dos soros pudessem interferir no resultado final da pesquisa, foi estabelecida uma amostra total de 453 cães (Tab. 1). A amostra total foi obtida de maneira proporcional para cada um dos nove Distritos Sanitários que compõem a cidade, segundo o censo canino realizado no mesmo ano pelo Centro de Controle de Zoonoses (CCZ-BH). Os animais selecionados foram cães saudáveis apresentados aos postos de vacinação na campanha de combate à raiva urbana organizada pelo $\mathrm{CCZ}$ $\mathrm{BH}$, durante o ano de 2005.

Tabela 1. Amostragem canina realizada durante a campanha de vacinação antirrábica, de acordo com as regionais da Prefeitura de Belo Horizonte, MG, 2005

\begin{tabular}{cccc}
\hline Regional & $\begin{array}{c}\text { População canina } \\
\text { estimada }(\%)\end{array}$ & $\begin{array}{c}\text { Amostra } \\
\text { calculada }(\%)\end{array}$ & $\begin{array}{c}\text { Amostra } \\
\text { obtida }(\%)\end{array}$ \\
\hline Barreiro & $42.334(13,40)$ & $50(13,55)$ & $67(14,79)$ \\
Venda Nova & $41.184(13,04)$ & $48(13,01)$ & $63(13,91)$ \\
Noroeste & $40.614(12,86)$ & $47(12,74)$ & $47(10,38)$ \\
Leste & $40.405(12,79)$ & $47(12,74)$ & $67(14,79)$ \\
Nordeste & $38.307(12,13)$ & $45(12,19)$ & $59(13,02)$ \\
Centro-Sul & $31.027(9,82)$ & $36(9,76)$ & $42(9,27)$ \\
Norte & $28.921(9,16)$ & $34(9,21)$ & $34(7,51)$ \\
Oeste & $28.909(9,15)$ & $34(9,21)$ & $38(8,39)$ \\
Pampulha & $24.123(7,64)$ & $28(7,59)$ & $36(7,95)$ \\
\hline Total & $315.824(100)$ & $369(100)$ & $453(100)$ \\
\hline
\end{tabular}

As amostras de sangue foram coletadas e transportadas em temperatura ambiente para um laboratório de sorologia, onde foram submetidas à centrifugação $(1500 \times \mathrm{x} g$ por 10 minutos) para obtenção do soro, o qual foi aliquotado em microtubos, separado e congelado a $-20^{\circ} \mathrm{C}$ até a realização do teste sorológico. Todas as 453 amostras de soro foram avaliadas pela RIFI, contra cinco antígenos brutos: Rickettsia rickettsii cepa Taiaçu, Rickettsia parkeri cepa At-24, Rickettsia amblyommii cepa Ac-37, Rickettsia felis cepa Pedreira e Rickettsia bellii cepa Mogi (Horta et al., 2006; Pinter e Labruna, 2006). A reação foi realizada conforme Labruna et al. (2007), e as amostras foram consideradas sororreagentes quando apresentavam títulos $\geq 64$. Todos os antígenos utilizados provieram de isolados de carrapatos, exceto Rickettsia felis, que foi isolada de pulgas.

Os soros foram diluídos a partir de 1:64 em PBS $(15 \mu \mathrm{L}$ do material diluído foi depositado sobre cada região demarcada das lâminas de RIFI) e incubados em câmara úmida a $37^{\circ} \mathrm{C}$ por 30 minutos, sempre na presença de controles positivo e negativo. As lâminas foram lavadas com solução de washing buffer e mantidas em cuba com a mesma solução durante 15 minutos, por duas vezes. Após secarem, foram incubadas a $37^{\circ} \mathrm{C}$ por 30 minutos com isotiocianato de fluoresceína conjugado com imunoglobulina $\mathrm{G}$ anticão (Sigma Diagnostics, St. Luis, Mo) na diluição de 1:600, novamente lavadas como descrito anteriormente e coradas em solução de washing buffer, mais 0,2\% de azul de Evans. Após completamente secas, foram cobertas com glicerina tamponada e lamínula para posterior leitura em microscópio com luz ultravioleta (Olympus BX60, Japan) com objetiva de 40X.

A prevalência de anticorpos anti-Rickettsia spp. observada no presente trabalho foi de $0,66 \%$ (3/453). Ao se considerar a utilização de antígenos de diferentes espécies de rickéttsias, os 
animais mostraram-se reagentes para Rickettsia rickettsii, Rickettsia parkeri e Rickettsia amblyommii (Tab. 2). Conforme interpretações previamente padronizadas (Labruna et al., 2007), determinou-se Rickettsia rickettsii como provável antígeno responsável pela infecção natural no cão identificado como BAR 19, uma vez que o título de anticorpos para essa espécie (1024) foi quatro ou mais vezes superior ao título para outras espécies (256 para Rickettsia parkeri e 128 para Rickettsia amblyommii). Para os demais soros reagentes, não foi possível determinar qual espécie foi responsável pela infecção natural, pois os animais identificados como VN 09 e VN 12 apresentaram títulos de 128 e 256 para Rickettsia rickettsii e 64 e 128 para Rickettsia parkeri, respectivamente. Nenhuma amostra de soro apresentou qualquer título para os antígenos de Rickettsia bellii ou Rickettsia felis.

Tabela 2. Títulos apresentados pela reação de imunofluorescência indireta (RIFI) para antígenos brutos de Rickettsia spp. em soros caninos de diferentes regionais administrativas da cidade de Belo Horizonte, MG

\begin{tabular}{ccccccc}
\hline \multirow{2}{*}{$\begin{array}{c}\text { Soro } \\
\text { canino }\end{array}$} & \multicolumn{5}{c}{ Título pela RIFI } & PAIHR \\
\cline { 2 - 5 } & Rickettsia & $\begin{array}{c}\text { Rickettsia } \\
\text { parkeri }\end{array}$ & $\begin{array}{c}\text { Rickettsia } \\
\text { amblyommii }\end{array}$ & Rickettsia felis & $\begin{array}{c}\text { Rickettsia } \\
\text { bellii }\end{array}$ & Plickettsii \\
\hline BAR 19 & 1024 & 256 & 128 & NR & NR & R. rickn \\
VN 09 & 128 & 64 & NR & NR & NR & \\
VN 12 & 256 & 128 & NR & NR & NR & \\
\hline
\end{tabular}

PAIHR: antígeno possivelmente envolvido em reação homóloga (título para determinada espécie de rickéttsia pelo menos quatro vezes maior que o título mais alto obtido para as demais espécies foi considerado homólogo à primeira espécie).

NR: soro não reagente a um título $\geq 64$.

O presente trabalho é o primeiro estudo de soroprevalência de infecção por Rickettsia spp. em cães da cidade de Belo Horizonte. Até então, a maioria dos estudos sorológicos sobre prevalência de anticorpos anti-Rickettsia spp. em humanos e hospedeiros amplificadores havia se concentrado em áreas endêmicas, onde a ocorrência de casos fatais se apresenta frequente. A escolha da capital mineira foi oportuna, uma vez que Minas Gerais é o estado que apresenta a maior ocorrência de casos de FMB no país, com notificações registradas em quase todas as áreas do estado.

Os cães são animais próximos dos humanos e podem desempenhar importante papel na cadeia epidemiológica da febre maculosa. Rhipicephalus sanguineus, principal carrapato de cães no Brasil, já demonstrou capacidade vetorial para agentes da febre maculosa em outros países (Demma et al., 2005). Essas informações revestem de importância trabalhos dessa natureza, haja vista que muitas capitais reúnem condições epidemiológicas tais que proporcionam potencial biótico para a ocorrência da doença, como, por exemplo, numerosa população canina (Tab. 1), o que possibilita estreito convívio entre pessoas, animais e carrapatos.
Os estudos de prevalência de anticorpos para rickéttsias do GFM em cães de área endêmica nos estados de Minas Gerais, São Paulo e Espírito Santo registraram resultados discrepantes, variando entre $8 \%$ e $69,6 \%$ (Lemos et al., 1994; Lemos et al., 1996; Pinter et al., 2008). A prevalência de cães sororreativos encontrada no presente trabalho $(0,66 \%)$ foi considerada baixa, mesmo quando comparada a resultados de prevalência $(12,9 \%)$ obtidos de área não endêmica (Lemos et al., 1996). A baixa prevalência encontrada está de acordo com as observações locais, onde nos últimos anos verificou-se um único caso humano de FMB notificado na cidade de Belo Horizonte (Calic, 2007 - comunicação pessoal, 2007 - FUNEDMG). Deve-se salientar, no entanto, que a circulação de rickéttsias na natureza é um processo dinâmico que envolve a participação de diferentes espécies de carrapatos e animais vertebrados, de maneira que a vigilância epidemiológica ativa deve ser adotada continuamente, a fim de determinar precocemente o surgimento de novas áreas endêmicas para riquetsioses, mesmo antes da ocorrência de casos humanos da doença. Na condição de hospedeiro para os carrapatos vetores da FMB, o cão pode ser utilizado como 
importante sentinela em estudos de vigilância epidemiológica.

Pode-se concluir que, sob as condições experimentais descritas e por ocasião da realização do trabalho, havia entre os cães de Belo Horizonte baixa circulação de Rickettsia rickettsii ou de outra espécie homóloga, o que sugere que a cidade não se comportava como área endêmica para FMB ou outra riquetsiose do GFM.

Palavras-chave: cão, Rickettsia, soroprevalência

\begin{abstract}
A cross-sectional study was conducted to determine the seroprevalence of anti-Rickettsia spp. in dogs from Belo Horizonte, MG. For this purpose, serum samples from 453 dogs were collected during the rabies vaccination campaign and tested by the indirect immunofluorescence assay (IFA) using five antigens: Rickettsia bellii, Rickettsia amblyommii, Rickettsia rickettsii, Rickettsia parkeri, and Rickettsia felis. The endpoint titer reacting with each antigen was determined and serum was considered positive if it reacted at the 1:64 dilution. Serum showing titer for a Rickettsia species at least four-fold higher than that observed for any other Rickettsia species was considered homologous to the first Rickettsia species. Only three $(0.66 \%)$ dogs reacted positively to at least one Rickettsia species and one serum showed to be homologous to R. rickettsii. These results showed a low prevalence of antibodies anti-Rickettsia spp. in dogs from Belo Horizonte city. However, other serosurvey needs to be performed for surveillance of the endemic status of the disease in the municipal district.
\end{abstract}

Keywords: dog, Rickettsia, seroprevalence

\section{REFERÊNCIAS BIBLIOGRÁFICAS}

BROUQUI, P.F.; BACELAR, F.; BARATON, G. et al. Guidelines for the diagnosis of tick-borne bacterial diseases in Europe. Clin. Microbiol. Infect., v.10, p.1108-1132, 2004.

DEMMA, L.J.; TRAEGER, M.S.; NICHOLSON, W.L. et al. Rock Mountain spotted fever from arizona an unexpected tick vector in Arizona. N. Engl. J. Med. v.353, p.587-594, 2005.

GUEDES, E.; LEITE, R.C.; PRATA, M.C.A. et al Detection of Rickettsia rickettsii in the tick Amblyomma cajennense in a new Brazilian spotted fever-endemic area in the state of Minas Gerais. Mem. Inst. Oswaldo Cruz, v.100, p.841-845, 2005.

HORTA, M.C.; LABRUNA, M.B.; DURIGON, E.L. et al. Isolation of Rickettsia felis in the mosquito Cell Line C6/36. Appl. Environ. Microbiol., v.72, p.17051707,2006

LABRUNA, M.B.; HORTA. M.C.; AGUIAR, D.M. et al. Prevalence of Rickettsia infection in dogs from the urban and rural areas of Monte Negro municipality, western Amazon, Brazil. Vector-Borne Zoon. Dis. v.7, p.249-255, 2007.

LEMOS, E.R.; MACHADO, R.D.; COURA, J.R. et al. Epidemiological aspects of the Brazilian Spotted Fever: serological survey of dogs and horses in an endemic area in the state of São Paulo, Brazil. Rev. Inst. Med. Trop. São Paulo, v.38, p.427-430, 1996.
LEMOS, E.R.; MACHADO, R.D.; COURA, J.R. Rocky Mountain spotted fever in an endemic area in Minas Gerais, Brazil. Mem. Inst. Oswaldo Cruz, v.89, p.497-501, 1994.

PHILIP, R.N.; CASPER, W.; BURGDORPER, W. et al. Serologic typing of rickettsiae of the spotted fever group by microimmunofluorescence. J. Immunol., v.121, p.1961-1968, 1978.

PINTER, A.; LABRUNA, M.B. Isolation of Rickettsia rickettsii and Rickettsia bellii in cell culture from the tick Amblyomma aureolatum in Brazil. N. Y. Acad. Sci., v.1078, p.523-529, 2006.

PINTER, A.; HORTA, M.V.; PACHECO, R.C. et al. Serosurvey for Rickettsia spp. in dogs and humans from a Brazilian spotted fever endemic area in the state of São Paulo. Cad. Saúde Pública, v.24, p.247252,2008

RAOULT, D.; ROUX, V. Rickettsioses as paradigms of new or emerging infectious diseases. Clin. Microbiol. Rev., v.10, p.694-719, 1997.

YU, X.J.; WALKER, D.H. The Order Rickettsiales. In: DWORKIN, M. (Ed). The Prokaryotes: an evolving electronic resource for the microbiology community. 3.ed. New York: Springer-Velag, 2003. Disponível em: http://link.springerny.com/link/service/books/10125. Acessado em: 27 abr.2004. 